\title{
Analysis from The Bank of China on The Crude Oil Treasure Incident
}

\author{
Bohan Sun ${ }^{1+}$, Cindy $\mathrm{Ma}^{2+}$, Wenzhi Sun ${ }^{3+}$, Yi zhai ${ }^{4+*}$ \\ ${ }^{1}$ School of economic and business, Monash University, Melbourne, VIC3145, Australia \\ ${ }^{2}$ Ridge High School, Basking Ridge New Jersey, 07920, United States \\ ${ }^{3}$ Penn State University park, State College, Pennsylvania, 16801, United States \\ ${ }^{4}$ School of Politics and Public Administration, Soochow University, Suzhou, Jiangsu, 215123, China \\ *Corresponding author.Email: eve.zhai@hotmail.com
}

${ }^{+}$These authors contributed equally to this work and should be considered co-first authors.

\begin{abstract}
On April 20, U.S. time, the price of the West Texas Intermediate (WTI) crude oil May 2020 futures contract fell to a negative approximately $\$ 38$, which caused the Bank of China (BOC) and the buyers of the Crude Oil Treasure a considerable loss. To avoid the incident in the future, this paper will focus on the mistakes of BOC and give our suggestions to Chinese banks. This paper uses specific data from BOC's announcements, Wind, and BEA database, and compares with other Chinese banks that avoided this disaster. We hope to impact the future development of Chinese banks and other institutions. We suggest new regulation and operations systems.
\end{abstract}

Keywords: Crude Oil Treasure, Bank of China, West Texas Intermediate, Risk Analysis, Risk Management

\section{INTRODUCTION}

With the development of financial market and the renewal of financial management concepts in China, more investors have chosen to diversify their assets, improved the risk bearing capability and tried new ways of investments, for example, entering the futures market. To satisfy the requirements of investors, many big banks in China introduce related products and service. Crude oil treasure is one of such products issued by Bank of China and is linked directly to international crude oil market.

However, in 2020, the WTI crude oil price fell to negative and there was an operational error in Bank of China, so many traders settled in negative price and lost more than billion yuan in total. The crude oil treasure incident of Bank of China in 2020 taught us a lesson. Current researches study the causes of negative oil price and the impacts of it at the macroscopic level, but few focus on just one of the market players and take a close look at crude oil treasure incident of Bank of China itself. That is our work. In the work, we first analyze the background of international market and what Bank of China did to deal with the incident. Then, we summarize its mistakes by making comparisons. Finally, we suggest new regulation and operations systems. We use Bank of
China as an entry point, do in-depth research on the incident and make a deep reflection. We hope Chinese banks and investors can learn a lesson.

\section{BACKGROUND}

\subsection{The background of "negative oil price"}

In February 2020, the COVID-19 broke out across the globe. Many countries adopted prevention and control measures to deal with it, such as closing the countries and acquiring the practice of "telecommuting", which caused the global economy to decline and global stock markets to plummet. In addition, the pandemic also had an adverse effect on the crude oil market. Due to the disruption of the global supply chain, global economic growth expectations drop dramatically. As a result, the demand for crude oil in the international market slowed down significantly. As shown in Figure 1, the International Energy Agency (IEA) reported a sharp decrease in the global daily demand for oil in 2020. According to the data, in the first two months of 2020, the international crude oil price dropped by more than $\$ 20 /$ barrel or more than $30 \%$. Moreover, only during the last week of February, the data from Figure 2 illustrate that the settlement price of WTI 
crude oil fell by $12.8 \%$, from $\$ 51.34 /$ barrel on February

24 to $\$ 44.76 /$ barrel on February 28 .

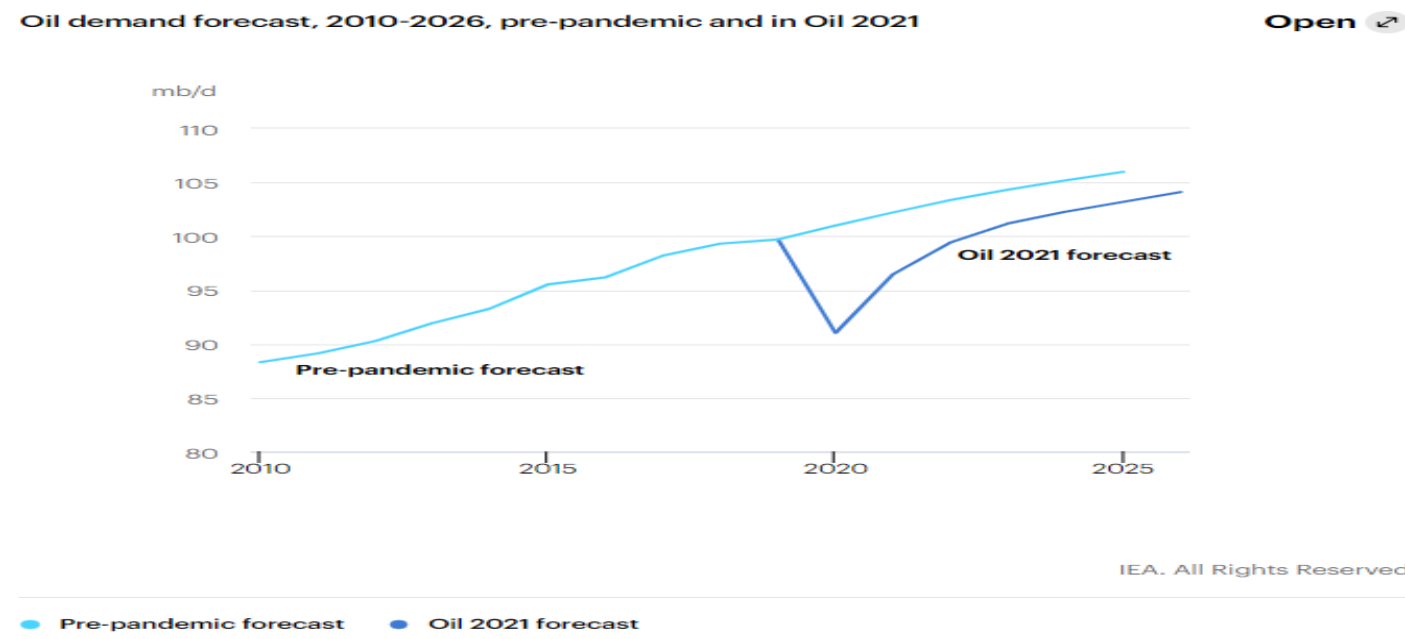

Figure 1 Oil demand forecast, 2021-2026, pre-pandemic and in Oil 2021 Source: IEA, Paris [1]

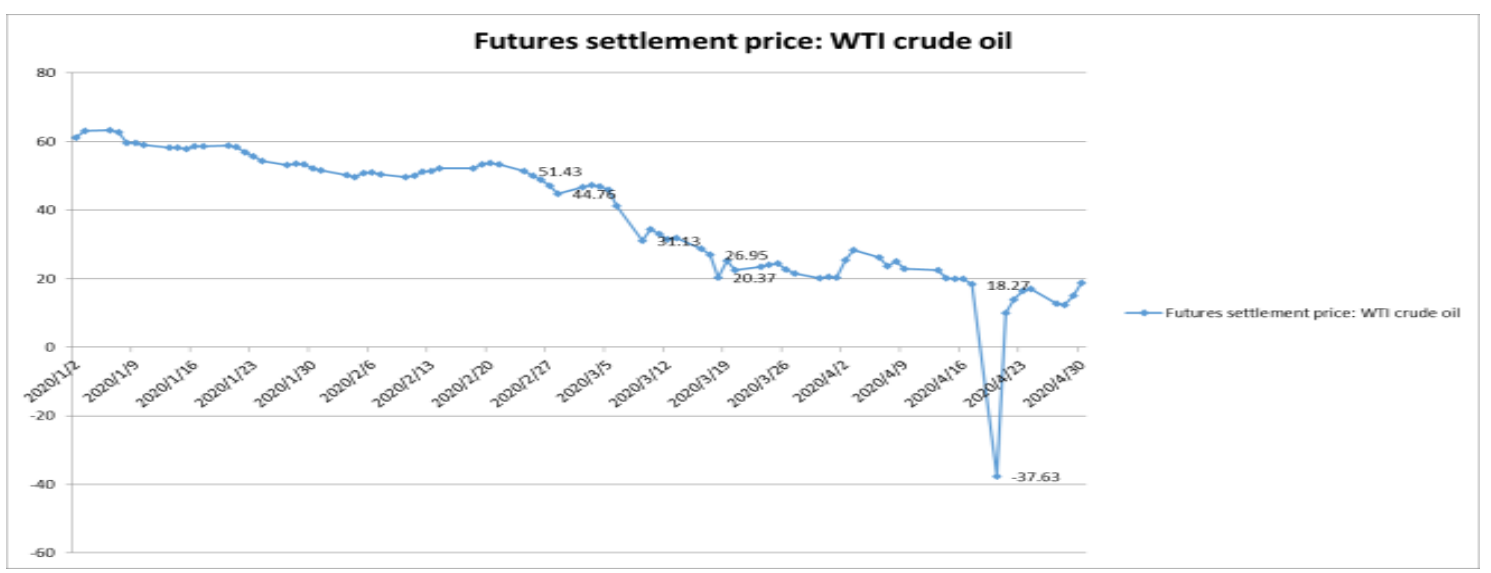

Figure 2 Futures settlement price: WTI crude oil (unit:\$/barrel) Source: Wind database

Affected by the epidemic and geopolitical factors, on March 6, 2020, the "OPEC+" oil-producing countries failed to reach an agreement to deepen production cuts, and OPEC and Russia were caught in a battle for oil market share. Due to pressure from the United States, "OPEC+" finally reached the first round of an agreement to reduce output by 9.7 million barrels on April 12, 2020. However, in the short term, it failed to solve the problem of soaring oil inventories caused by an imbalance between supply and demand [2]. On March 9, 2020, the plunge of the U.S. stock market triggered a circuit breaker and hit circuit breaker levels again on March 12 and March 16. With widespread panic in the international financial market, on March 18, the settlement price of crude oil fell to $\$ 20.37 /$ barrel, which can be showed from Figure 2.

Now, let us emphasize the transaction system of the crude oil futures market. On April 15, 2020, Chicago Mercantile Exchange (CME) clearing issued an announcement to clearing member firms and claimed that recent market events raised the possibility that specific NYMEX energy futures contracts could trade or be settled at negative or zero trade prices. In addition, options on these futures contracts could be listed with negative or zero strike prices [3]. To summarize, this announcement by CME makes negative oil prices possible.

Due to pessimistic market expectations and the new CME announcement, the WTI crude oil settlement price fell at a low level, but still at a positive price.

Since the decreasing demand and increasing supply of oil led to insufficient land for oil storage, on the last trading day, many investors did not choose to move their positions, and 11 billion barrels of oil remained. At that time, supply exceeded demand, and the future price was rising in an upward-sloping curve (Contango), and the price was expected to decrease. That was why people who brought long failed to sell their contracts and had to keep the oil. The only choice for them was to burn the oil because there was no space. However, the fine of American environmental law was high, and they ended up in resting order and closing positions. People who brought short caught the chance and kept asking for the lower price, 
so people who brought long were forced to sell their contracts at low prices and finally lost the game. The "air force and more" situation appeared, causing prices in the futures market to fall sharply. As a result, the settlement price of crude oil became negative at $-\$ 37.63 /$ barrel for the first time in history on April 20, 2020, EST, as shown in Figure 2. On the next day, many speculators who spotted an arbitrage opportunity and wanted to do bargainhunting entered the market again and brought the contract. Demand exceeded supply and the future price followed a downward-sloping curve (Backwardation). Therefore, the price drove up and returned to a positive level.

Additionally, another reason for the negative price was that because of the little storage capacity, the cost was higher and higher before 2020, April 20. The traders even preferred to accept the negative oil contract price rather than storing the oil. As a result, the people who brought the contract finally let the trade price became $\$-38$.

\section{2. "Crude Oil Treasure" incident}

Influenced by the negative price of WTI crude oil, the financial product "Crude Oil Treasure" (developed by BOC) caused losses to many investors and quickly sparked controversy.

In January 2018, BOC launched the "Crude Oil Treasure" product to provide domestic individual customers with trading services linked to overseas crude oil futures. Among them, American crude oil varieties are linked to the first-line contract of Texas Light Crude Oil (WTI) futures of Chicago Mercantile Exchange (CME). Individual customers need to submit $100 \%$ margin to handle "crude oil treasure", leverage trading is not allowed. As a market maker, BOC provides quotations and carries out risk management [4].

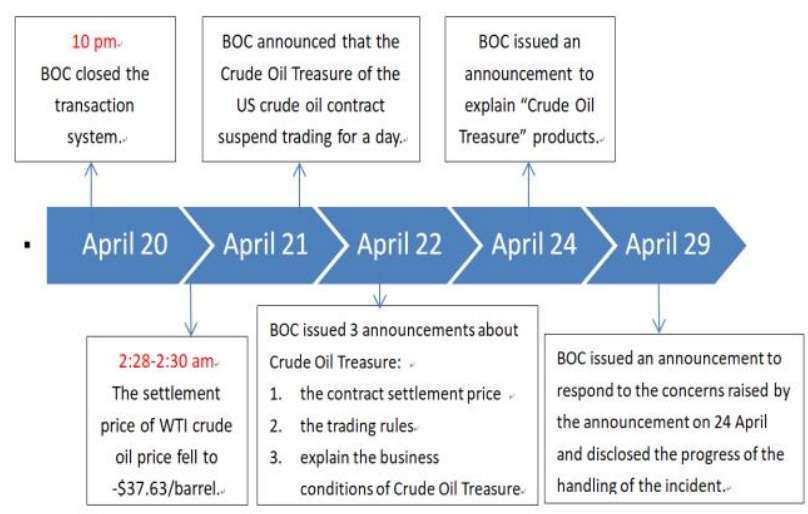

Figure 3 Timeline of BOC (Beijing time) Source: BOC

Figure 3 shows what BOC did the day before and how BOC coped with the incident later. According to the agreement, April 20 was the last trading day of Crude Oil Treasure U.S. crude Oil contract in May of that month, and the closing time was 22:00 Beijing time. In the early morning of April 21(Beijing time), the price of WTI crude oil for The May contract fell sharply, falling to an unprecedented low of around $-\$ 40 /$ barrel. However, facing such a big event, BOC lacked foresight and contingency plans and even failed to respond timely and accurately. At 22:00 Beijing time on April 20, 2020, BOC closed the transaction system and started to move the warehouse only one day before the delivery was due. BOC spent almost 24 hours checking and verifying the exact crude oil price. Chinese consumers' rage took BOC three more days to explain the "Crude Oil Treasure" product and its current conditions. Moreover, seven days had passed when BOC responded to social concerns and disclosed the progress, and fourteen days had passed when BOC announced to negotiate with customers and handle the loss of investors.

\subsection{Legal judgment}

In response to violations of laws and regulations related to the risk events of BOC's "Crude Oil Treasure", China Banking and Insurance Regulatory Commission (CBIRC) claimed to give serious punishments to BOC and demand it to make rectifications. According to the announcement issued by CBIRC on December 15, 2020, $\mathrm{BOC}$ and its branches were fined a total of 50.5 million yuan; two general managers of global marketing department of BOC were warned and fined 500,000 yuan, and two related deputy general managers and senior traders of the global marketing department of BOC were warned and fined 400,000 yuan [5]. On December 31, 2020, the People's Court of Gulou District, Nanjing City, Jiangsu Province publicly pronounced the first instance of the civil litigation case involving BOC's "Crude Oil Treasure" incident and ruled that the BOC would bear all the losses of the plaintiff's warehouse wear and $20 \%$ of the principal loss, return the balance of the deposits deducted from the plaintiff's account, and pay the corresponding capital occupation fee. The second instance, on 2021, February 10, upheld the original judgment [6].

\section{ANALYSIS}

\subsection{Attribute}

Because the Chinese financial market seems immature, there exist wide opportunities to earn profit. As supported by outstandingly high domestic savings - a personal saving rate of $44.9 \%$, the Chinese banking system has accumulated nearly $\$ 50$ trillion in assets [7]. While other first-world countries like the United States, only possess a personal saving rate of $9.4 \%$. Moreover, the value of saving deposits at all depository institutions in the U.S. is $\$ 10.63$ trillion, almost $1 / 5$ of the Chinese banking system [8].

Therefore, China has a huge saving market in its banking system. As they receive bank deposits, they pay bank interest rates. Each year, Banks like BOC must pay 
large sums of interest to its consumer. BOC wondered if there exists a method that he could not only avoid paying interest but also earn a profit. As a result, in Jan 2018, BOC came up with the plan of "crude oil treasure", which satisfies the above two conditions. Crude oil treasure referred to the structural product linking to domestic and overseas crude oil futures contracts issued by BOC to individual customers. Unlike the U.S. market who had negative experiences with the banking system, Chinese consumers hold confidence in the bank's credit. Hence, when BOC issued the "Crude Oil Treasure "along with its over-appealing advertising, it quickly became a popular choice of investment [9].

In the viewpoint of BOC, such a scenario could not be better: Not only does he not need to pay annual saving interest on these consumers with no potential risk --- but he could also earn a profit by taking out loans. For instance BOC can lend the money in the crude oil treasure account to others, but no need to pay interest back. In this case, BOC's profit would be the interest rate spread between the lender and the borrower, since the interest rate that BOC must pay the crude oil treasure consumers is 0 . This indicates that implementing crude oil treasure allows BOC to earn a higher-than-normal profit just through a bank's daily functioning of lending money.

The crude oil treasure has no potential risk to $\mathrm{BOC}$ because $\mathrm{BOC}$ required its consumers to pay a hundred percent of earnest money in full. BOC's response to crude oil treasure product stated that "When the market price is not negative, the long position will not trigger the forced liquidation" [4]. This means as long as crude oil prices remain positive, the BOC will take zero risks when consumers aim for long. The worst case is that consumers have lost all their principal, yet consumers, not BOC suffer these losses. Many may ask, what about when consumers aim for short? BOC has considered this case in advance. According to BOC's crude oil treasure contract, when consumers sell shorts, and the earnest money falls below $20 \%$ of the original $100 \%$, BOC will apply forced liquidation to the account. In other words, whenever there is a fluctuation greater than $20 \%$ between the opening price and the settlement price and the consumer is short selling, the consumer's account will be forced liquidated. After that, the consumer is required to repay the $80 \%$ losses. If the consumer fails to do so, this loss will be recorded as a personal debt to BOC [8].

In conclusion, as long as the crude oil price remains above zero, the crude oil treasure is guaranteed with a free yield to BOC.

\subsection{Comparison}

Many Chinese banks also launched products similar to BOC's crude oil treasure. When WTI announced that crude oil price had fallen to $-\$ 38$ in April 2020, why did only BOC suffer major losses?

\subsubsection{Delivery date}

The biggest mistake that BOC had made in the crude oil treasure incident is the settlement date. BOC decided upon a settlement date that is very close to the crude oil futures' expiry date. Since the West Texas Intermediate (WTI) Crude Oil Futures Contract ends on the $25^{\text {th }}$ calendar day, BOC should terminate the contract month at least four days prior. Since April 25 is a Saturday, which is not a business day, the May future contract is supposed to terminate on April 21. In the usual case, most professional institutions will roll over at least four days prior to the expiration date. For instance, the Commercial Bank of China (ICBC) always rolled over on the 14th. However, BOC chooses to roll over on the last day, which is April 21.

This is a severe and unprofessional mistake. Banks with similar products already leave the market, so what kind of consumers stay in the market? The answer is consumers with spot delivery capacity. Common examples are crude oil companies with a deep understanding of the market, a capacity to transfer the oil, and an insightful vision into the future of crude oil. They are speculators who are ready to grab on opportunities. After the oil price went to $\$-38$ around 2:00 am, they will quickly hoard these cheap crude oils and rebound. Thus, their profit is the difference of crude oil price when the May contract terminates.

Because BOC could not take spot delivery, it is not among this group of investors. At first sight, BOC saw the opportunity that if they wait until the last minute, the price of the contract will be extremely close to the spot price, and they can utilize this advantage to track spot price in the next month. However, there also exist vast risks. As most investors already rolled over, the liquidity of the futures contracts on the last delivery date will be extremely low. Little or no investors will be willing to take BOC's large amount of pending orders, the uncertainty of the rollover significantly increased.

In addition, taking spot delivery is not an option for BOC. Because BOC chose to roll over on the last trading before the May contract terminates, the storage costs of crude oil are extremely high around delivery dates. According to the Chicago Mercantile Exchange (CME), the crude oil storage level at Cushing has reached its peak of 65 million barrels during April 2020. In fact, crude oil storage futures contract spiked up from $\$ 0.07$ in March 2020 to $\$ 0.55$ in April 2020 [10]. Therefore, BOC must force liquidate the crude oil treasure accounts at any cost because the storage costs are more expensive. This decision leads to over $\$ 85$ million in losses in the crude oil treasure incident.

BOC is not an expert in the crude oil market, but it is arrogant enough that to refuse rollover prior to the expiration date. One reason is that BOC believes that such loss is not a big deal to the total assets of BOC, and another 
reason is that they always believe that the Chinese government will assist them. This further reflects the irresponsible attitude of BOC to customers because they put their own interests before their customers.

\subsubsection{Margin Closeout}

Another aspect that indicates the BOC's unprofessionalism was its crude oil treasure product's margin close on April 20, 2020. The BOC has placed the trading hours in between 9 am. and $10 \mathrm{pm}$. Beijing time. This means that the margin is closeout after $10 \mathrm{pm}$. If an investor sets up a pending order after $10 \mathrm{pm}$. Beijing time, he will not get a response until the following day's 9 am. This trading time interval that BOC set up is unreasonable. Since $10 \mathrm{pm}$. Beijing time is $10 \mathrm{am}$. in the Chicago Board of Trade. It should be noted that the U.S. trading hours are between 9:30 am. and 4:00 pm. In other words, when BOC closed its crude oil treasure margin at $10 \mathrm{pm}$, at Beijing time, the U.S. market has just started trading. It is commonly known that the market tends to release press between 10 am and $2 \mathrm{pm}$ New York time. Therefore, the market price fluctuates the most intense at this time interval throughout the day. This means that investors hold a high probability of gaining good profits but dangerous risks. However, during that time interval, BOC already closed its trading hours. On that occasion, the investors of crude oil treasure could only watch their money flowing out of their account, but they can do nothing about it.

Besides, when the crude oil treasure incident happens, $\mathrm{BOC}$ responded that margin closeout at 10 p.m. Beijing time does not mean BOC will start to rollover at 10 p.m. Beijing time. Therefore, BOC calculated the delivery price base on the NYMEX West Texas Intermediate (WTI) Crude Oil futures settlement price of the exchange futures contract on the day. Not only that the consumers of crude oil treasure not allowed to trade after 10 p.m. Beijing time, but they also had to pay for the settlement price between the time interval of 9 a.m. Beijing time to 4 a.m. Beijing time. (On April 20, 2020, BOC calculated the delivery price based on the average price of the time interval 2:28 am-2:30 am, Beijing time, which was right when WTI crude oil price fell into $-\$ 38)$.

Meanwhile, ICBC was much more reasonable regarding their posted trading hours for their Account Based-crude oil. As stated on ICBC's official website, the trading hours are "Monday: 9:00-24:00, Tuesday to Friday: 0:00- 4:00, 9:00-24:00, Saturday: 0:00-4:00" [4]. Compared with BOC's trading hours, ICBC's post covered most of the U.S. trading time interval. Especially on Tuesday through Friday, ICBC posted two shifts, which embodies their serious work attitude. Not only that ICBC has a logical schedule, but they also never failed on margin closeout according to their recorded history. As a result of such rigorous conduct, ICBC completed the rollover on April 14, 2020, while BOC failed.

\subsubsection{False advertisement}

In BOC's 2018 publicity for its new product, the crude oil treasure, the advertisement stated: "Is there a profitable but interesting product for a new investor without any financial knowledge? Absolutely! That is Crude Oil Treasure!" [4]. Nevertheless, anyone who has conducted a little research on the crude oil treasure would have known, such a product possesses high risk, and therefore its target customer is certainly not beginner investors. The crude oil treasure links to the domestic and overseas futures contract. As a result, we regard that BOC's crude oil treasure and futures have similar risks. In the futures market, there exist great leverages. Thus, speculators faced increased risk and margin calls that could lead to potential losses. Though BOC's crude oil treasure was not leveraged, consumers must pay a hundred percent in total. This means that if consumers suffer losses in BOC's crude oil treasure, they could have lost all their money in the account. Hence, BOC's crude oil treasure is not an investment that investors can play with without any financial knowledge.

On the other hand, the Industrial and Commercial Bank of China (ICBC) also launched a paper crude product called Account-based Cruel Oil. However, ICBC maintained a much more rigorous attitude towards selecting their target consumer. On ICBC's official website, it states that the Account-based cruel oil is suitable for "individual customers who have the full civil capacity and corresponding risk tolerance and meet product suitability assessment." Evidently, ICBC imposed a certain threshold upon its consumers. Only consumers who fulfilled the above three requirements may enter the paper crude market.

While ICBC succeeds in its job, the BOC has failed to accomplish this job. Using false publicity to induce "young" investors, in which it reflects the unprofessionalism of BOC.

\subsubsection{Irresponsible Reaction}

When the Chicago Mercantile Exchange (CME) published an announcement that allows the existence of negative prices for certain energy futures contracts, including crude oil futures, on April 15, 2020, BOC fails to respond to this change in policy on time. BOC continues to set the delivery date on 20 April, 2020, after which CME's new policy was made effective. In the meantime, ICBC set its delivery date on April 14, 2020, which is before the effective date of this announcement.

In addition, BOC failed to recognize the underlying risk behind CME's newly released announcement. BOC's crude oil treasure would not conduct a forced closeout only if the crude oil treasure price is positive. In other words, BOC should realize that there exists high potential risk after $\mathrm{CME}$ announced that crude oil futures price 
could be negative. However, BOC neither changed its regulation rule nor notified its consumers of the impending risk after April 15, 2020. In comparison, ICBC reminded its customers of such risk beforehand, which fulfilled their responsibility.

From this response, we may conclude that BOC's design of the crude oil treasure may work in a normal environment. However, in extreme conditions, its regulators are not flexible enough to adjust the existing rules in a timely manner. BOC did not fulfill its responsibilities to its customers, and at the same time, this demonstrated that BOC is still inexperienced in dealing with the oil futures contracts.

\subsection{Regulatory Issues}

In Crude Oil Treasure's case, it shows the wrong operations of BOC when it dealt with unstable market risks. Traditionally, the market risks of BOC are affected by price changes. In recent years, the interest rate marketization in China is accelerating. At the same time, the competitions among debt and credit capitals become intense, and the autonomous pricing power of commercial banks become stronger. Therefore, the interest rate spread becomes smaller, which means the profit of commercial banks depending on the interest-rate spread between deposit and loan loan-deposit interest margin is affected, so the market risks are also affected. Based on the attribution of Crude Oil Treasure and the comparisons in the earlier parts, we will discuss BOC's compliance and regulatory issues from three aspects.

\subsubsection{Non-compliance of sales and publicity management}

BOC failed to achieve works like compliance publicity and marketability review. From 2018 to 2020, BOC intended to describe Crude Oil Treasure as a low risk commodity investment. Its advertisement said that "Whether the price of crude oil rises or falls, it always can make money". What is more, in 2018, BOC's financial manager claimed in Beijing Television of Finance (BTV): "To a certain extent, Crude Oil Treasure can act as a hedging tool for your daily consumption. If the investor holds a certain crude oil position, this fee will be hedged when the oil price rises. Also, the Crude Oil Treasure is not leveraged, and the risk is not particularly high" [11]. From BOC's advertisements and publicities, it existed problems of untrue publicity and insufficient risk disclosure. The buyers did not receive the accurate information from BOC's publicity, which led many uneducated Chinese investors to buy Crude Oil Treasure. Most of them were blindly who had little knowledge about investment and finance.

\subsubsection{Irregular product management}

BOC's risk assessment was not rigorous, and it did not apply pressure tests. BOC assessed the risk level of Crude Oil Treasure as level R3. According to China Banking Regulatory Commission Order 2011 No. 5's report "Administrative Measures for the Sales of Wealth Management Products of Commercial Banks", Products with level R3 always have low risks [4]. At the beginning of April, 2020, Chicago Mercantile Exchange (CME) announced that a negative price of Crude Oil Treasure could exist. However, BOC did not change its risk assessment after this announcement and failed to give the risk notices which is Crude Oil Treasure was exceeded the customer's risk tolerance, which may lead to the risk of shorting the position, and the customer should sell and close the position as soon as possible.

BOC was too confident about this investment since they believed that the government would help them no matter what happened, which made them unprofessional and incompetent. The most deadly consequence of this was that they calculated the wrong settlement day. During this incident, BOC showed its unprofessional operations which should not happen in this one of the biggest banks in the world. Apparently, the operators and managers ignored to the right settlement date. According to the West Texas Intermediate Crude Oil Futures Contract, if the $25^{\text {th }}$ day of the month is not a business day, the settlement date should be four days prior to the $25^{\text {th }}$ day of the month. On April 25, it is Saturday, which means the final trade day should be the $21^{\text {th }}$ day of the month. However, According to BOC's announcement on the last trading day of each contract of crude oil treasure products in 2020, the last trade day is 20th which was one day earlier than the date of expiration on the WTI future contract [4]. The decision of rollover from BOC was an unprofessional action. Buyers did not have enough time to consider their investment and options, so it could be concluded that the wrong and irresponsible settlement date was the most significant factor that caused the huge loss.

\subsubsection{Improper risk management}

As we discussed before, other banks like Industrial and Commercial Bank of China and China Construction Bank set their shift date to seven days prior to April 21, which could make sure that buyers can reduce the loss at the first time. However, BOC did not keep up to date and set the settlement date one day before the delivery date, which did not provide enough time for buyers to shift. According to the contract, when the contract expires, the bank will carry out position shifting or maturity netting in accordance with the method specified by the investor in advance on the contract expiry processing day. Shift refers to closing all current contracts held by investors and opening the next contracts at the same time; Netting refers to only closing all current contracts held by investors. In 
the operations of shifting and netting, the contract's settlement price will be set by BOC regarding the settlement price of the corresponding futures contract announced by the CME. The futures exchange calculates the day's settlement price based on the average price from 2:28 am to 2:30 am Beijing time. Other banks shifted to the May future contract seven days earlier than settlement date at the expense of some possible opportunities, which successfully avoided the danger. However, BOC underestimated the danger of the future market and wrongly designed the shift date, which was not responsible to its consumers. Uneducated buyers did not have the ability to react in one day.

The occurrence of the risk event of Crude Oil Treasure customers' wear-out risk originated from the announcement of BOC on April 3 that the crude oil treasure U.S. crude oil 2005 contract on April 20 will refer to the settlement price formed by the WTI crude oil futures May contract on April 20, U.S. time -37.63 USD/barrel for settlement or relocation. The settlement price of WTI crude oil futures is to use the last 3 minutes of 14:28-14:30 (Eastern Time) on the exchange to determine the daily settlement price. This moment is already more than 4 hours after the end of the last trading moment on the last trading day of the American Crude Oil 2005 contract, that is, more than 4 hours after the contract expires. After the price of Crude Oil Treasure fell below 20\%, BOC did not take any liquidation action, which caused a great number of losses to investors. This was because BOC used Trade at settlement (TAS) order which made it could not take action of liquidation. TAS helps buyers to use settlement price to trade with others during the trading time period. The price of the future market is constantly changing. $\mathrm{BOC}$ is too big to process orders immediately, which causes that every client's prices are different. As a result, at that time, BOC chose TAS to settle all the prices at the final price.

\section{SUGGESTIONS}

\subsection{Establish sound management and a supervision system}

In fact, in the department of BOC's system, each department has their own tasks respectively. The sales department pursues investment blindly and does not fix the content of related contracts timely according to the market changes and the risk control department only bases on the original contract content to examine the creditworthiness of investors and the legitimacy of the sale without being aware of possible or imminent risks outside the product. Even though the research and analysis department predicted possible risks, each department could not make timely and effective responses and coordination, which resulted in significant losses. Therefore, it is necessary to establish a perfect supervision system to manage the operation of all products. It needs a special department to regulate the contract from the sale of products to the end. According to the changes and forms of the market, The Bank needs to make timely modifications in order to ensure that the products adapt to the current market environment. For the jet lag problem of the market in different countries, banks should also set up a professional person to operate and stare the trading market. Because in the event of a "treasure" of crude oil, BOC was no related person working after $10 \mathrm{pm}$ in Beijing time, but the American market trading hours were in Beijing time of the morning. So it is necessary to set up professional staffs and competent traders in working on the international market.

\subsection{Strengthen guidance and establish mechanisms}

In China, the futures market is still early, and most investors do not have much investment experience and skills. Therefore, in most cases, the tendency and decision of investors largely depend on the advice of investment institutions and the products launched by banks. However, investors invest blindly and seek more profits with high leverage that will lead to high risks. Therefore, training and guidance for investors are essential. In the product sales process, the words and deeds of sales personnel must be standardized that must not mislead and deceive investors and try to use understandable words to inform investors of the product's possible risks and operational procedures. Banks should conduct training for investors to master basic market knowledge and the ability of independent judgment. Banks also need to establish a reasonable "appropriate matching" mechanism which will make a comprehensive analysis of every investor before investment, including the investor's assets, liabilities, and income situation. It is based on the analysis report about investors grading to recommend the products that meet their affordability. And periodical reviewing the investors' situation, banks should be notified promptly, and relevant changes should be suggested if they found that the investor's ability rating is no longer suitable for the current products

\subsection{Set up insurance and hedging mechanisms and conduct regular pressures tests}

Banks should be responsible for the safety of the products they issued. Appropriate insurances and hedging mechanisms are essential for banks to prevent risks. For example, in the case of "crude oil treasure", the bank is worried about the loss caused by the decline of crude oil price so that the bank can buy a put option in the futures market. Once the price of crude oil drops significantly, the bank can enter the derivatives market and sell the option at the agreed price to hedge the loss. Alternatively, buying insurance for the product, once the price drops to the insurance coverage, the loss of the product can be borne by the insurance company, but the corresponding product 
cost will also increase. These precautions should be accompanied and explained to investors at the time of offering. In fact, BOC has set up a margin system, but the loss happened resulting in a quickly decreasing price of crude oil and moving too slowly of BOC, so the necessary insurance is essential. During the process of production, regular pressures tests should be carried out to ensure that the product can adapt to the current market environment. It is basing on the test results to make a timely change, including changes in contract details and regulations, in an effort to match current market conditions without affecting investors' returns.

\subsection{Government regulators step up monitoring and management efforts}

National government departments, such as the Banking and Insurance Regulatory Commission, should better improve market rules and systems to ensure investors' legitimate rights and maximum interests in the case of loss. More market information should be disclosed to make the market more transparent and fair. More individual investors participating in the market and market manipulation by investment institutions should be strictly prohibited to push the development of the economy and market. After risks and losses occur, government departments should timely intervene and adjust the market in accordance with relevant laws and regulations. It can not only maintain the stability of the market and society but also improve the image of the government in front of the public. Through the "Crude Oil Treasure" incident, BOC only needs to pay back $20 \%$ of funds from investors that were less cost than the others. Therefore, the government should enforce the level of punishment and solve the problems from investors as quickly as possible, which can eliminate the panic of investors and change the bad market phenomenon and reform the relevant system. Overall, the government is the creator of the market system and the maintainer of the market environment. A fair, transparent, and orderly market environment can also reflect the government's ability and national image.

\section{CONCLUSION}

This paper focuses on the Crude Oil Treasure incident in many aspects, including the causes, process, and suggestions. This paper analyzes these things through graphs and evidence from official places like BOC and $\mathrm{CME}$, restoring the whole incident and comparing with other banks. We concluded that BOC had serious problems on regulating sales and publicity, Implementing products managements, and processing risk management. In this case, BOC was highly unprofessional and carelessly on its business and operations, which can bring us many meaningful advices on fixing the system and management of the banks. Banks should improve the efficiency and accuracy of the systems, make good publicities to educate investors, and build professional financial operations. We hope Chinese Banks and other institutions are able to learn this lesson and improve their competitiveness in the future.

\section{REFERENCES}

[1] OilDemandForecast,2010-2026, Pre pandemic andin Oil 2021. (n.d.). IEA 2020, data-and-statistics. chart.

[2] Jing, Zhang., \& Pei, Wang. (2020). Analysis on the underlying causes of WTI negative price. International Petroleum Economics. China International United Petroleum \& Chemicals, Vol.28, no.6.

https://tow.cnki.net/kcms/detail/detail.aspxfilename $=$ GJJJ202006009\&dbcode $=$ CRJT_CJFD\&dbname $=$ CJFDLAST2020\&v $=$.

[3] CME Clearing. (2020, April 8). Cme clearing plan to address the potential of a negative underlying in certain energy options contracts. CME Group. https://www.cmegroup.com/notices/clearing/2020/0 4/Chadv20-152.html.

[4] Bank of China. (2020, April 24). Bank of China's explanation of "Crude Oil Treasure" products. Bank of

China. https://www.bankofchina.com/custserv/bi2/202004/t 20200424 17793210.html?

keywords= $\%$ E5\%8E $\% 9 \mathrm{~F} \% \mathrm{E} 6 \% \mathrm{~B} 2 \% \mathrm{~B} 9 \% \mathrm{E} 5 \% \mathrm{AE}$ $\% 9 \mathrm{D}$.

[5] CBIRC. (2020, December 5). China Banking and Insurance Regulatory Commission, China investigated and dealt with the risk events of Bank of China's "Crude Oil Treasure" products according to law.

http://www.cbirc.gov.cn/cn/view/pages/ItemDetail.h tml docId $=947272 \&$ itemId $=915$.

[6] Wu, R. (2021, February 10). Two civil appeals involving the Bank of China "Crude Oil Treasure" incident, the original verdict was upheld in the second instance. Judgement. https://

www.sohu.com/a/450346431 162758.

[7] Fernandez-Perez, A., Fuertes, A.-M., \& Miffre, J. (2020). Understanding the negative pricing of the Nymex WTI crude oil May 2020 futures contract. SSRN Electronic Journal. https:/doi.org/ $10.2139 /$ ssrn.3748321.

[8] Personal Saving Rate. (2021, July 30). BEA Bata. https://www.bea.gov/data/income-saving/ personal-saving-rate.

[9] Zhiquan, C., \& Huaibin, H. (2021, April 1). Why Bank of China Became the Only Bank in China that Suffered from Negative Pricing of the WTI Crude Oil 
May 2020 Futures Contract. Frontiers in

Economics and Management.

https://www.airitilibrary.com/Publication/

alDetailedMesh?docid=P20200813001-202104-

202104150001-202104150001-355-359

[10] Hui, B., Fengbin, Lu., \& Yujie, Wei. (2020, September). Lessons from the Event of Personal Account Crude Oil Product of Bank of China: A Case Study on Financial Inovation. Management Review. Management Comment. https://xueshu.baidu.com/usercenter/paper/ showpaperid=1m120640jn6m00y0aa590xh0ek1618 06\&site $=$ xueshu_se.

[11] Jintoushou. (2020, April 27). The controversial Crude Oil Treasure. Baijiahao. https://baijiahao.baidu.com/s?id=166509015440455 $3655 \& w f r=$ spider $\&$ for $=p c$ 